\title{
Stent versus Coronary Artery Bypass Surgery in Multi-Vessel and Left Main Coronary Artery Disease: A Meta-Analysis of Randomized Trials with Subgroups Evaluation
}

\author{
Pedro José Negreiros de Andrade, 1,2 João Luiz de Alencar Araripe Falcão, 1,2 Breno de Alencar Araripe Falcão, 1,2 \\ Hermano Alexandre Lima Rocha ${ }^{1,2}$ \\ Hospital Dr. Carlos Alberto Studart Gomes de Messejana, ${ }^{1}$ Fortaleza, CE - Brazil \\ Universidade Federal do Ceará, ${ }^{2}$ Fortaleza, CE - Brazil
}

\begin{abstract}
Background: Comparison between percutaneous coronary intervention (PCI) using stents and Coronary Artery Bypass Grafting (CABG) remains controversial.

Objective: To conduct a systematic review with meta-analysis of PCI using Stents versus CABG in randomized controlled trials.

Methods: Electronic databases were searched to identify randomized trials comparing PCI using Stents versus CABG for multi-vessel and unprotected left main coronary artery disease (LMCAD). 15 trials were found and their results were pooled. Differences between trials were considered significant if $p<0.05$.

Results: In the pooled data $(n=12,781), 30$ days mortality and stroke were lower with $\mathrm{PCl}(1 \%$ versus $1.7 \%, p=0.01$ and $0.6 \%$ versus $1.7 \% p<0.0001)$; There was no difference in one and two year mortality $(3.3 \%$ versus $3.7 \%, p=0.25 ; 6.3 \%$ versus $6.0 \%, p=0.5)$. Long term mortality favored CABG $(10.6 \%$ versus $9.4 \%, p=0.04)$, particularly in trials of DES era $(10.1 \%$ versus $8.5 \%, p=0.01)$. In diabetics $(n=3,274)$ long term mortality favored CABG $(13.7 \%$ versus $10.3 \% ; p<0.0001)$. In six trials of LMCAD $(n=4,700)$ there was no difference in 30 day mortality $(0.6 \%$ versus $1.1 \%, p=0.15)$, one year mortality (3\% versus $3.7 \%, p=0.18)$, and long term mortality (8.1\% versus 8.1\%) between PCI and CABG; the incidence of stroke was lower with $\mathrm{PCI}(0.3 \%$ versus $1.5 \% ; \mathrm{p}<0.001)$. Diabetes and a high SYNTAX score were the subgroups that influenced more adversely the results of $\mathrm{PCI}$.
\end{abstract}

Conclusion: Compared with CABG, PCI using Stents showed lower 30 days mortality, higher late mortality and lower incidence of stroke. Diabetes and a high SYNTAX were the subgroups that influenced more adversely the results of PCI. (Arq Bras Cardiol. 2019; 112(5):511-523)

Keywords: Myocardial Revascularization/mortality; Percutaneous Coronary Intervention; Drug-Eluting Stents; Stents; Coronary Vessels; Randomized Controlled Trial; Meta-Analysis.

\section{Introduction}

Percutaneous coronary intervention (PCl) using stents and coronary artery bypass grafting (CABG) are well-accepted alternatives for treatment of coronary artery disease (CAD). A large number of randomized controlled trials (RCT) comparing the two procedures were published. ${ }^{1-23}$ Most studies were underpowered to evaluate isolated endpoints like death, stroke and acute myocardial infarction (AMI). Several meta-analyses were subsequently carried out, pooling results in order to overcome this limitation. ${ }^{24-31}$ The largest meta-analysis included a limited number of drug-eluting stent (DES) era trials and/or

Mailing Address: Pedro José Negreiros de Andrade •

Rua Francisco Holanda, 992 apt. 1101. Postal Code 60130-040, Dionísio

Torres, Fortaleza, CE - Brazil

E-mail: pedroneg@gmail.com, pedroneg@gmail.com

Manuscript received March 05, 2018, revised manuscript August 06, 2018, accepted September 05, 2018

DOI: $10.5935 / a b c .20190027$ included also single vessel disease and balloon era trials. On the other side, modern meta-analysis included a lower number of trials (only of DES era) and evaluated specific group of patients. ${ }^{28-32}$ The objective of this study was to perform a systematic review of RCT comparing stents ( bare-metal and drug-eluting) versus CABG in multi-vessel and/or left main coronary disease (LMCAD) pooling data of mortality at different periods of time and using meta-regression analysis to evaluate sub-groups.

\section{Methods}

\section{Search strategies}

Randomized studies comparing $\mathrm{PCl}$ with Stents versus CABG in multivessel lesions and/or obstruction of left main CAD published between January 1990 and December 2017 were searched in the databases MEDLINE and Cochrane library and in bibliographic references published on the subject. The search terms used were: "coronary stents" and "coronary artery bypass surgery" and "randomized controlled trial". 
Inclusion criteria

Clinical trials were included in the review if they were randomized, if had compared $\mathrm{PCI}$ with stents versus $\mathrm{CABG}$, if included exclusively multi-vessel and/or LMCAD and if had a follow up of at least 1 year. We did not limit our search to DES trials because bare-metal stents (BMS) are still frequently used in many developing countries, had the peculiarity of evaluating patients with less complex coronary artery disease and there is no definitive evidence that BMS are inferior to DES in the outcome mortality. Figure 7 show a flow diagram of the search strategy in the databases. We identified a total of 15 RCT that satisfied the requirements: AWESOM ${ }^{1}$, ERACI II, ${ }^{2,3}$ MASS II, ${ }^{4-6}$ SOS,${ }^{7,8}$ ARTS,,${ }^{9,10}$ LE MANS, ${ }^{11}$ SYNTAX, ${ }^{12-14}$ CÁRDia, ${ }^{15}$ Boldriot et al., ${ }^{16}$ PRECOMBAT, ${ }^{17,18}$ Va-Cards, ${ }^{19}$ FREEDOM, ${ }^{20}$ BEST, ${ }^{21}$ NOBLE $^{22}$ and EXCEL. ${ }^{23}$ Three reviewers (PJNA, ATA and JLAF) assessed the quality of the studies using the Cochrane Collaboration's tool.

\section{Data extraction}

Two reviewers (JLAAF and PJNA) obtained the data from the studies, examining abstracts, results, tables, appendices and figures. A third author (BAAF) checked the results.

The main outcomes evaluated were all case-mortality, stroke, AMI and new revascularization. Mortality was divided into early mortality, mortality at one year and late mortality. Early mortality was defined as percentage of deaths that occurred in the first 30 days after the procedure, including deaths after randomization but before the procedure. Late mortality was defined as percentage of deaths reported in the last publication, after at least three years of follow-up. For the incidence of stroke, we considered the events occurring up to 1 year after the procedure. In twelve studies we obtained the results up to 30 days, in 2 studies ${ }^{9,12}$ up to 1 year and in one ${ }^{21}$ this observation was unavailable. For the incidence of myocardial infarct, we considered the reported up to one year of the procedure. AMI were reported in 13 trials. ${ }^{2-5-15}$ We did not consider in the pooled data the results of NOBLE because it excluded perioperative myocardial infarct in the majority of the patients.

New revascularization was divided in any form of new revascularization ( $\mathrm{PCl}$ or $\mathrm{CABG}$ ) and new revascularization by alternative procedure ( $\mathrm{PCl}$ for patients of the $\mathrm{CABG}$ group or $\mathrm{CABG}$ for the patients of the $\mathrm{PCl}$ group).

\section{Data synthesis}

The characteristics of patients from the eligible studies were obtained through a weighted average of published data. For pooling results of mortality and stroke, the numerator was the number of events and the denominator the total of patients. The total of patients was the number of patients effectively followed, including the deaths. Trials were divided into DES era trials and BMS era trials. Trials that used both types of stents ${ }^{11,15}$ were classified as DES era trials. We evaluated separately the results of studies in the left main coronary artery and late mortality in the subgroup of patients with diabetes. We also performed analysis of combined major adverse cardiac and cerebrovascular events (MACCE) and assessed the variables age, gender, presence of diabetes, SYNTAX score, and compromised ejection fraction in subgroups based on data published in five trials. Combined MACCE comprised death, $\mathrm{AMI}$, and new revascularization. In order to aggregate the outcomes of mortality and stroke, as well as those of MACCE (in subgroups), we considered whenever possible the absolute number of events and the number of patients followed up. Otherwise, percentages were transformed into absolute numbers.

\section{Statistical analysis}

We measured the relative risk and the risk difference after grouping the results of each outcome. In order to assess the statistical significance of the differences between the DES and the surgery groups, we performed a meta-analysis using the Mantel-Haenszel method, with a random-effect model. We calculated the heterogeneity of the studies using Cochran's Q test and the significance of the measure of the meta-analytic effect using the $\mathbf{Z}$ test. Finally, we performed a meta-regression analysis using diabetes, age, gender, ejection fraction, and syntax scores as factors. The differences between the results in the $\mathrm{PCl}$ and $\mathrm{CABG}$ groups were considered significant if $p<0.05$. The statistical analyses were performed using the program Review Manager (RevMan), version 5.3 (Copenhagen: The Nordic Cochrane Centre, The Cochrane Collaboration, 2014) and SPSS for Windows $\checkmark 23$, IBM Inc. In order to represent the heterogeneity of the studies, we constructed Forest plots. We used the risk difference to plot these graphs since this is a more stable index. The possibility of publication bias was assessed by visual inspection of funnel plots.

\section{Results}

\section{Studies Characteristics}

The studies (table 1 ) included a total of 12,781 patients $(6,382$ in the CABG group and 6,399 in the $\mathrm{PCl}$ group). All studies were, considered of quality $A$ or $B$ in terms of adequate randomization, adequate concealment and inexistence of selection bias, but not in terms of adequate making. In all studies, the $\mathrm{PCl}$ and $\mathrm{CABG}$ groups were similar, with the exception of VaCards where the $\mathrm{PCl}$ group had a higher incidence of the previous revascularization (in most of the cases a previous $\mathrm{PCI}$ ) and showed a higher percentage of patients with ejection fraction $<55 \%$. The mean age of the patients was 64 years; $74 \%$ were male; $42 \%$ were diabetics; $28 \%$ were smokers; $64 \%$ were hypertensive. Unstable angina was the clinical presentation in $34 \%$; mean ejection fraction was $58 \%$. With the exception of AWESOME, all studies tended to exclude patients with previous CABG. The mean SYNTAX score was 26. According to number of arteries affected $20 \%$ had two vessel disease, $43 \%$ had three-vessel disease and $37 \%$ had LMCAD (alone or associated with diseases of other arteries). In the CABG group, at least one arterial graft was used in $90 \%$ of the patients. In trials of the BMS era surgery was done almost always using on-pump technique; in trials of the era, the DES off-pump technique was used in $28 \%$ of the patients. Some characteristics of the studies deserve special mention: 
ERACI II included more them $90 \%$ of patients with unstable angina. AWESOME included only patients with high surgical risk; MASS II included predominantly stable angina and had a clinical arm; LE MANS used drug-eluting and BMS, reserving the DESs for left main coronary arteries with a reference diameter < $3.8 \mathrm{~mm}$; CARDia used initially BMS and only assessed patients with diabetes and multivessel disease; SYNTAX evaluated left main coronary artery obstruction and multivessel disease and used first-generation DESs (TAXUS); FREEDOM and VA CARDS exclusively assessed patients with diabetes and multivessel disease; BEST evaluated patients with multivessel disease and used only everolimus-eluting stents; the study by Boudriot et al. evaluated left main coronary artery obstruction and used only sirolimus-eluting stents; EXCEL evaluated left main coronary artery obstruction and used only everolimus-eluting stents; NOBLE evaluated left main coronary artery obstruction and used mostly a biolimus-eluting stent.

\section{Outcomes}

The results are summarized in Figures 1 to 6 . Regarding 30-day mortality, the results favoured $\mathrm{PCI}(1 \%$ versus CABG $1.7 \%, p=0.01)$, but the trials showed moderate overall heterogeneity $\left(\mathrm{I}^{2}=49 \%\right)$. The heterogeneity was particularly higher in BMS era trials $\left(I^{2}=83 \%\right)$ and could be attributed to the significant inferior results of surgery in ERACI II and AWESOME. The incidence of stroke was lower with PCI $(0.6 \%$ versus $C A B G 1.7 \%, p<0.0001)$, with trials showing low heterogeneity $\left(\mathrm{I}^{2}=0\right)$. There was no difference in mortality up to one year $(\mathrm{PCl} 3.3 \%$ versus CABG 3.7\%, $\mathrm{p}=0.25$ ) or up to two year ( $\mathrm{PCl} 6.3 \%$ versus CABG $6.0 \%, p=0.5$ ). Long-term mortality showed a trend to superiority of CABG $(10.6 \%$ versus $9.4 \%, p=0.04)$, with trials showing moderate heterogeneity $\left(\mathrm{I}^{2}=25 \%\right)$. The differences were significant in trials of DES era $(10.1 \%$ versus $8.5 \%, p=0.01)$. After excluding FREEDOM (that included only diabetics) the overall difference in long-term mortality between PCI and CABG became not significant $(10.2 \%$ versus $9.4 \%, p=0.17)$. The incidence of myocardial infarct was lower with CABG (PCl $6.4 \%$ versus CABG $5.3 \%$ at one year and $\mathrm{PCl} 8,8 \%$ versus CABG $6.7 \%$ after 3 or more years), but the trials showed high heterogeneity.

In 6 studies of LMCAD $(\mathrm{n}=4700)$, there was no difference in 30 days mortality $(0.6 \%$ versus $1.1 \%, p=0.15)$ between $\mathrm{PCl}$ and $\mathrm{CABG}$, but the incidence of stroke was significantly lower after $\mathrm{PCl}(0.3 \%$ versus $1.1 \%, \mathrm{p}=0.007)$. There was no difference in one-year mortality ( $3 \%$ versus $3.7 \%, p=0.18$ ) or long-term mortality ( $8.1 \%$ versus $8.1 \%$ ) between $\mathrm{PCl}$ and CABG.

Nine trials $(n=4394)$ reported long-term mortality in diabetics (AWESOME, ARTS, ERACII, MASS II, SOS, SYNTAX, CARDia, FREEDOM and BEST). After pooling of results, CABG was associated with significantly lower long-term mortality (13.7\% versus $10.3 \%$ CABG, $p<0.0001)$; After excluding the diabetic patients of these nine trials the overall difference in long-term mortality between $\mathrm{PCl}$ and $\mathrm{CABG}$ was no longer significant (9.2\% versus $9.2 \%)$.

The data regarding new revascularization are shown in figure 5. The superiority of surgery over $\mathrm{PCl}$ was consistent in all 15 trials. However, if we consider the risk of new revascularization by alternative procedure there was a trend to superiority of $\mathrm{PCl}$ in ARTS and in all studies of DES era.

\section{Subgroups results}

Five trials reported long-term results of major Adverse Composite Events (death, myocardial infarct and stroke) in subgroups. In three of them (SYNTAX, PRECOMBAT and BEST) the results were obtained through the collaborative meta-analysis of Lee et al. ${ }^{24}$ (Figure 4). The pooled data showed that CABG, compared to $\mathrm{PCl}$, was associated with a lower incidence of MACCE (18.4\% vs $14.4 \%, p<0.0001)$. The subgroups in which $\mathrm{PCl}$ had worse results, when compared with CABG, by meta-regression analysis were presence of diabetes $(23 \%$ versus 17.5, $\mathrm{p}<0.0001)$ and a high SYNTAX score (22.7 vs. $16.3 \%, \mathrm{p}=0.001)$. There was no difference between $\mathrm{PCI}$ and CABG in non-diabetics (14.1\% versus $12.3 \%, p=0.11)$, low SYNTAX score patients ( $14.1 \%$ vs. $13.3 \%$ scores, $p=0.4)$ and LMCAD patients $(14.7 \%$ vs $14.1 \%, p=0.5)$. Female sex and old age less significantly influenced the results. Left ventricular dysfunction did not influence the results. Figure 5 shows that the meta-Adjusted value of $\mathrm{p}$ for diabetes was 0.03 (adjusted for age or sex) and 0.09 (adjusted for SYNTAX score). The same figure shows that the meta-adjusted value of $\mathrm{p}$ for SYNTAX score was 0.03 (adjusted for diabetes).

\section{Discussion}

To our knowledge this meta-analysis is the most comprehensive and up to date overview of randomized trials that compared coronary stents (DES and BMS) versus CABG. It is also the only major meta-analysis of the stent era that evaluated mortality at different times (up to 30 days, up to one year and after three or more years of follow-up). Another peculiarity of the present meta-analysis was the statistical meta-regression analysis of sub-groups.

The superiority of $\mathrm{PCl}$ on 30 days mortality is in accord with the New York state Registry ${ }^{33}$ and with the meta-analysis of Palmerini et al. ${ }^{32}$ This superiority should be seen with caution considering the heterogeneity of the trials and cannot be extended to patients with high SYNTAX score, considering the mortality curve of the study of Cavalcante et al. ${ }^{30}$ The significant difference, favoring $\mathrm{PCl}$ found in the incidence of stroke is a relevant finding. A recent study showed that, after death (relative weight 0.23 ), stroke is the most feared event for patients (relative weight 0.18), being considered more important them longevity (relative weight 0.17 ), myocardial infarct (relative weight 0.14 ) and risk of repeat revascularization (relative weight 0.11 ). ${ }^{34}$ The lack of difference in intermediate mortality was an expected finding, having been reported in almost all trials.

The trend superiority of surgery in long-term mortality was shown in other meta-analysis ${ }^{26,29,31}$ and is probably related to the higher percentage of diabetics in recent trials. Our results of long-term mortality (HR 1.13) were similar to the results of Smit el al. ${ }^{26}$ (HR 1.11) and Lee et at. ${ }^{29}$ (HR 1.18). They were much less unfavourable to $\mathrm{PCI}$ them the reported by Benedetto et al (HR 1.5). ${ }^{31}$ The reason for this is that 


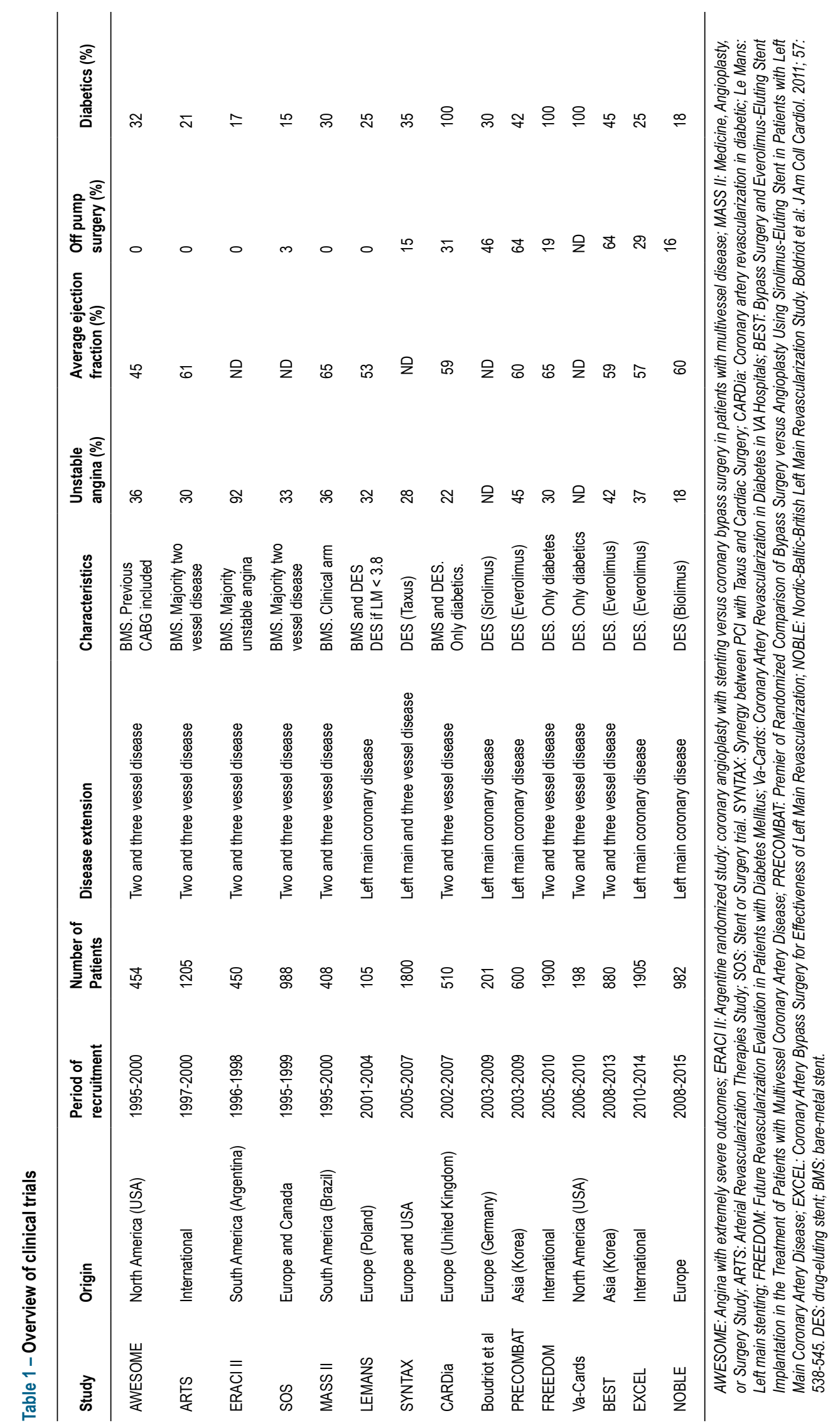




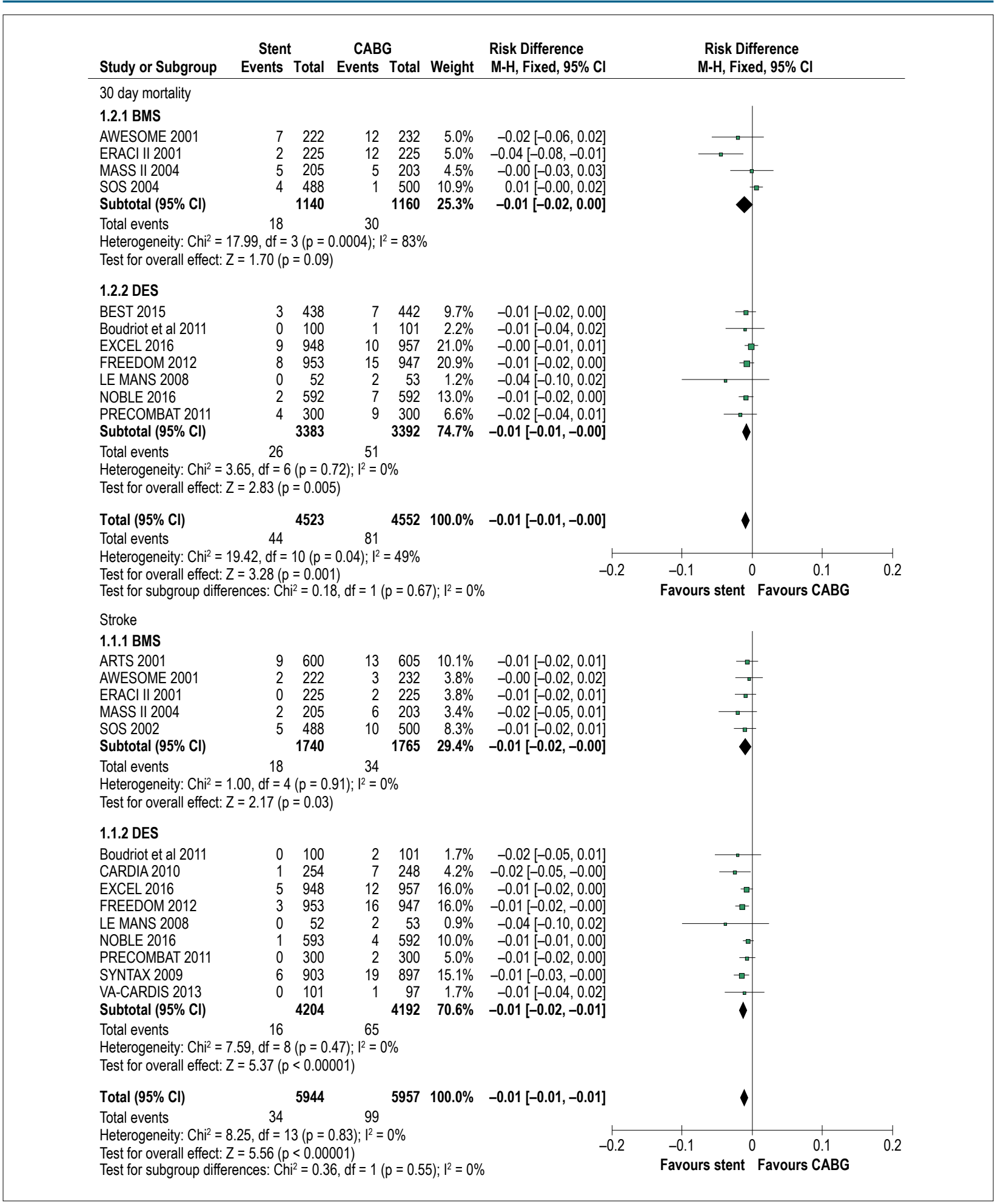

Figure1 - Stent versus CABG: 30 days mortality (top) and stroke (bottom). The size of each box is proportional to the number of patients of the trial. The bars represent $95 \%$ confidence interval. The diamond represents the syntheses of results. DES: trials of the drug-eluting stent era. BMS: trials of the bare-metal stent trials era. CABG: coronary artery bypass grafting. ARTS: Arterial Revascularization Therapies Study; AWESOME: Angina with extremely severe outcomes; ERACI II: Argentine randomized study: coronary angioplasty with stenting versus coronary bypass surgery in patients with multi-vessel disease; MASS II: Medicine, Angioplasty, or Surgery Study; SOS: Stent or Surgery trial; BEST: Bypass Surgery and Everolimus-Eluting Stent Implantation in the Treatment of Patients with Multi-vessel Coronary Artery; Boldriot, trial of Boldriot et al: J Am Coll Cardiol. 2011; 57: 538-545. CARDia: Coronary artery revascularization in diabetic; LE MANS: Left main coronary artery stenting; EXCEL: Coronary Artery Bypass Surgery for Effectiveness of Left Main Revascularization; FREEDOM: Future Revascularization Evaluation in Patients with Diabetes Mellitus NOBLE, Nordic-Baltic-British Left Main Revascularization Study; PRECOMBAT: Premier of Randomized Comparison of Bypass Surgery versus Angioplasty Using Sirolimus-Eluting Stent in Patients with Left Main Coronary Artery Disease; SYNTAX: Synergy between PCI with Taxus and Cardiac Surgery; Va-Cards: Coronary Artery Revascularization in Diabetes in VA Hospitals. 


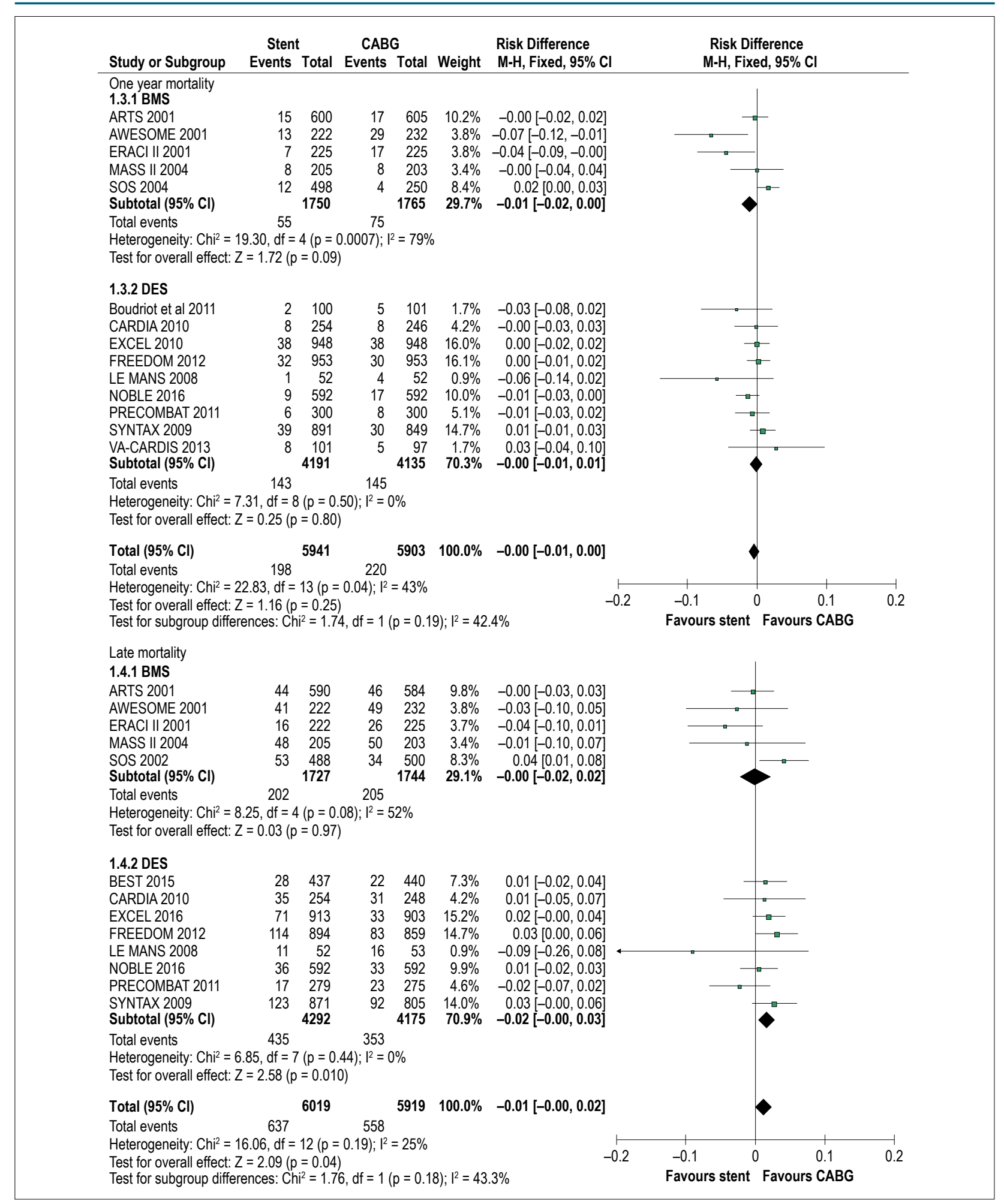

Figure 2 - STENT versus CABG: One-year mortality (top) and late mortality (bottom). The size of each box is proportional to the number of patients of the trial. The bars represent $95 \%$ confidence interval. The diamond represents the syntheses of results. DES: trials of the drug-eluting stent era; BMS: trials of the bare-metal stent trials era; CABG: coronary artery bypass grafting; ARTS: Arterial Revascularization Therapies Study; AWESOME: Angina with extremely severe outcomes; ERACI II: Argentine randomized study: coronary angioplasty with stenting versus coronary bypass surgery in patients with multi-vessel disease; MASS II: Medicine, Angioplasty, or Surgery Study; SOS: Stent or Surgery trial; BEST: Bypass Surgery and Everolimus-Eluting Stent Implantation in the Treatment of Patients with Multi-vessel Coronary Artery; Boldriot, trial of Boldriot et al: J Am Coll Cardiol. 2011; 57: 538-545. CARDia: Coronary artery revascularization in diabetic; LE MANS: Left main coronary artery stenting; EXCEL: Coronary Artery Bypass Surgery for Effectiveness of Left Main Revascularization; FREEDOM: Future Revascularization Evaluation in Patients with Diabetes Mellitus; NOBLE: Nordic-Baltic-British Left Main Revascularization Study; PRECOMBAT: Premier of Randomized Comparison of Bypass Surgery versus Angioplasty Using Sirolimus-Eluting Stent in Patients with Left Main Coronary Artery Disease; SYNTAX: Synergy between PCl with Taxus and Cardiac Surgery; Va-Cards: Coronary Artery Revascularization in Diabetes in VA Hospitals. 


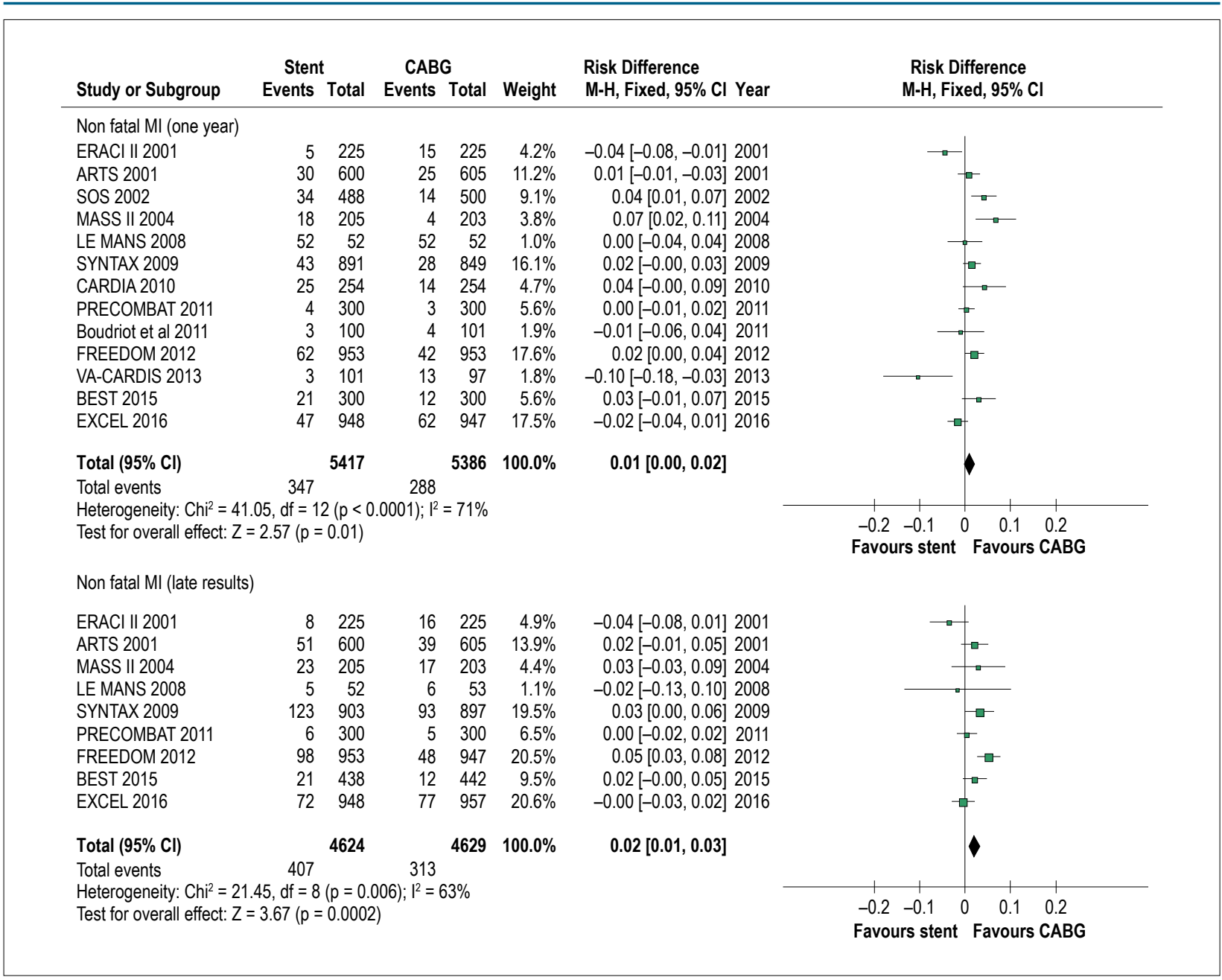

Figure 3 - Stent versus CABG: Acute myocardial infarct at one year (top) and after three or more years (bottom). The size of each box is proportional to the number of patients of the trial. The bars represent $95 \%$ confidence interval. The diamond represents the syntheses of results. DES: trials of the drug-eluting stent era; BMS: trials of the bare-metal stent trials era; CABG: coronary artery bypass grafting; ARTS: Arterial Revascularization Therapies Study; AWESOME: Angina with extremely severe outcomes; ERACI II: Argentine randomized study: coronary angioplasty with stenting versus coronary bypass surgery in patients with multi-vessel disease; MASS II: Medicine, Angioplasty, or Surgery Study; SOS: Stent or Surgery trial; BEST: Bypass Surgery and Everolimus-Eluting Stent Implantation in the Treatment of Patients with Multi-vessel Coronary Artery; Boldriot, trial of Boldriot et al: J Am Coll Cardiol. 2011; 57: 538-545. CARDia: Coronary artery revascularization in diabetic; LE MANS: Left main coronary artery stenting; EXCEL: Coronary Artery Bypass Surgery for Effectiveness of Left Main Revascularization; FREEDOM: Future Revascularization Evaluation in Patients with Diabetes Mellitus; NOBLE: Nordic-Baltic-British Left Main Revascularization Study; PRECOMBAT: Premier of Randomized Comparison of Bypass Surgery versus Angioplasty Using Sirolimus-Eluting Stent in Patients with Left Main Coronary Artery Disease; SYNTAX: Synergy between PCI with Taxus and Cardiac Surgery; Va-Cards: Coronary Artery Revascularization in Diabetes in VA Hospitals.

Benedetto et al excluded LMCAD (that presented similar results of mortality with the two methods of revascularization) and BMS trials (that involved patients with less complex CAD), did not include AWESOME and included two years results of VaCards. Another reason for the significant worse comparative results of $\mathrm{PCl}$-stent in the meta-analysis of Benedetto et al. was that diabetics represented $66 \%$ of their population. Recently a pooled analysis of an individual database from 11 trials was published by Head et al..$^{35}$ and their overall results are similar to ours. Small differences can be explained by the fact that they included late results of VACards and did not include AWESOME, CARDia, Boldriot and LEMANS.
LMCAD was, for a long time, an indication type III for PCl, but this concept began to change after four trials showed similar results in mortality. ${ }^{11,12,16,17}$ However, AHA/ACC guidelines have accepted PCI only as class IIA or IIB indication for LMCAD and yet, only for patients at high surgical risk. In the present study, we found results similar in mortality, while the incidence of stroke was lower, favouring PCI. Our findings are similar to the collaborative study of Head et al and to the meta-analysis of Palmerini et al. ${ }^{32}$ This study provided also mortality results in subgroups, showing that in patients with low SYNTAX SCORE there was a trend to higher long-term mortality with CABG (HR, 0.68, Cl 0.43-1.08; $\mathrm{p}=0.09$ ); intermediate SYNTAX score patients had similar 


\begin{tabular}{|c|c|c|c|c|c|}
\hline Study or Subgroup & $\begin{array}{l}\text { Stent } \\
\text { Events }\end{array}$ & Total & $\begin{array}{l}\mathrm{CAB} \\
\text { Events }\end{array}$ & Total & Weight \\
\hline \multicolumn{6}{|l|}{ One year mortality } \\
\hline Boudriot et al 2011 & 2 & 100 & 5 & 101 & $4.3 \%$ \\
\hline EXCEL 2016 & 38 & 948 & 38 & 957 & $40.5 \%$ \\
\hline LE MANS 2008 & 1 & 52 & 4 & 53 & $2.2 \%$ \\
\hline NOBLE 2016 & 9 & 592 & 17 & 592 & $25.2 \%$ \\
\hline PRECOMBAT 2011 & 6 & 300 & 8 & 300 & $12.8 \%$ \\
\hline SYNTAXLM 2013 & 15 & 357 & 15 & 348 & $15.0 \%$ \\
\hline Total $(95 \% \mathrm{Cl})$ & & 2349 & & 2351 & $100.0 \%$ \\
\hline \multicolumn{6}{|c|}{$\begin{array}{l}\text { Heterogeneity: } \text { Chi }^{2}=3.64, d f=5(p=0.60) ; l^{2}=0 \% \\
\text { Test for overall effect: } Z=1.29(p=0.20)\end{array}$} \\
\hline \multicolumn{6}{|l|}{ Late mortality } \\
\hline EXCEL 2016 & 71 & 913 & 53 & 903 & $41.6 \%$ \\
\hline LE MANS 2008 & 11 & 52 & 16 & 53 & $2.4 \%$ \\
\hline NOBLE 2016 & 36 & 592 & 33 & 592 & $27.1 \%$ \\
\hline PRECOMBAT 2011 & 17 & 279 & 23 & 275 & $12.7 \%$ \\
\hline SYNTAXLM 2013 & 42 & 357 & 50 & 348 & $16.2 \%$ \\
\hline Total $(95 \% \mathrm{Cl})$ & & 2193 & & 2171 & $100.0 \%$ \\
\hline $\begin{array}{l}\text { Total events } \\
\text { Heterogeneity: } \text { Chi }^{2}= \\
\text { Test for overall effect }\end{array}$ & $\begin{array}{r}177 \\
d f=4(p \\
01(p=1\end{array}$ & $\begin{array}{l}=0.20) \\
1.00)\end{array}$ & $\begin{array}{rl} & 175 \\
2 & 33 \%\end{array}$ & & \\
\hline
\end{tabular}

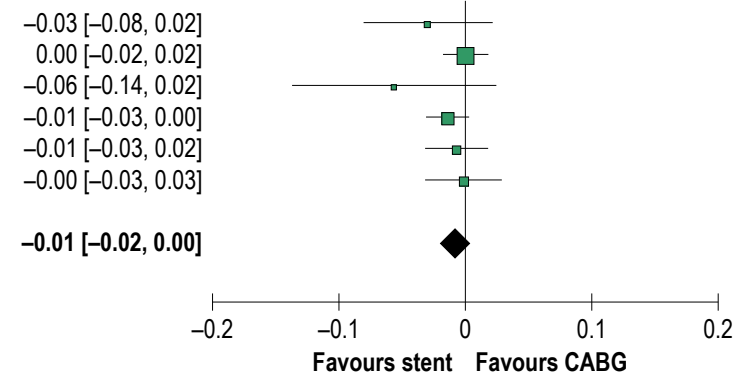

$0.02[-0.00,0.04]$

$-0.09[-0.26,0.08]$

$0.01[-0.02,0.03]$

$-0.02[-0.07,0.02]$

$-0.03[-0.08,0.02]$

$0.00[-0.02,0.02]$

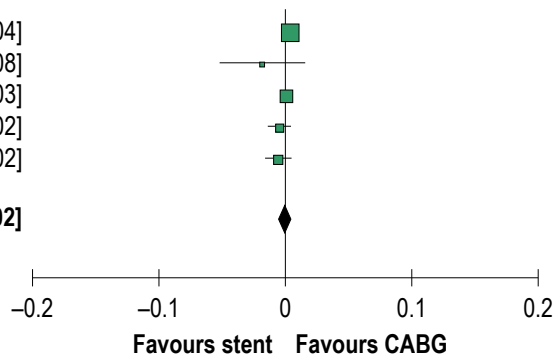

Figure 4 - Stent versus CABG in left main coronary artery disease: one-year mortality (top) and long-term mortality (bottom). The size of each box is proportional to the number of patients of the trial. The bars represent $95 \%$ confidence interval. The diamond represents the syntheses of results. ULMCAD: unprotected left main coronary artery disease. CABG: coronary artery bypass graft. LE MANS: Left Main coronary artery stenting study; SYNTAX LEMANS: subgroup of ULMCAD of SYNTAX (Synergy between PCI with Taxus and Surgery); PRECOMBAT: Premier of Randomized Comparison of Bypass Surgery versus Angioplasty Using Sirolimus-Eluting Stent in Patients with Left Main Coronary Artery Disease; EXCEL: Coronary Artery Bypass Surgery for Effectiveness of Left Main Revascularization; NOBLE: Nordic-Baltic-British Left Main Revascularization Study. Boldriot: Boldriot et al: J Am Coll Cardiol. 2011; 57: 538-545.

results (HR 1.16, $\mathrm{Cl} 0.51-264, \mathrm{p}=0.49)$. Considering this, we believe that $\mathrm{PCI}$ indications for LMCAD in AHA/ACC guidelines may be modified in near future.

Diabetic patients are a present challenge for $\mathrm{PCl}$. A more diffuse atherosclerotic disease is a possible explanation for the worse comparative results of $\mathrm{PCl}$ in this population. Our results suggest that there is still a superiority of surgery over $\mathrm{PCl}$ in long-term mortality, even in the DES era. There is a hypothesis that the greater mortality of $\mathrm{PCI}$ compared to CABG in diabetic patients may be attributed to the presence of more complex lesions in diabetic patients and, not to the metabolic disturbance. The fact that in the subgroup analysis of MACCE results (Figure 5) the meta-Adjusted value was 0.09 (adjusted for SYNTAX score) supports this hypothesis.

This review was not aimed to compare the results of BMS and DES for several reasons: in BMS trials patients had less complex angiographic lesions (average of 2.3 stents per patient in ARTS and SOS trials versus 3.8 stents per patient in SYNTAX, FREEDOM, BEST, PRECOMBAT and CARDia trials) and had a small percentage of diabetic patients. Otherwise, medical adjunctive treatment and results of surgery for patients with failed $\mathrm{PCl}$ also evolved. But the good comparative results of $\mathrm{PCl}$ in $\mathrm{BMS}$ era trials suggest that for patients with less complex lesions, or patients with unstable angina (ERACI II trial) or high surgical risk (AWESOME trial) initial $\mathrm{PCl}$ is a good alternative to CABG.

In terms of major adverse composite events, the analysis of subgroups showed that diabetes and a high SYNTAX score were the most important factors to influence adversely the results of $\mathrm{PCl}$. Presence of left ventricular dysfunction did not influence the results, but the number of patients with this finding was small. A high SYNTAX score was an independent risk factor for adverse outcomes, even when adjusted for diabetes, but diabetes was not an independent risk factor for adverse outcomes when adjusted for SYNTAX score.

In the present review despite the clear superiority of CABG in the outcome of new revascularization, it is possible to notice the progressive improvement of $\mathrm{PCl}$ results. This was particularly striking when we consider the outcome "new revascularization by alternative procedures", in which there was a tendency to superiority of PCI in the DES era.

The evidence presented here should be used to inform patients, helping them in choosing the more adequate form of revascularization in multi-vessel and LMCAD. Some patients may prefer having $\mathrm{PCl}$ to avoid the higher morbidity and short-term mortality of surgery. Other patients may put greater emphasis on the superiority of surgery regarding long-term mortality. However, $\mathrm{PCl}$ using second generation DES may still be considered as an alternative to CABG, 


\section{Original Article}

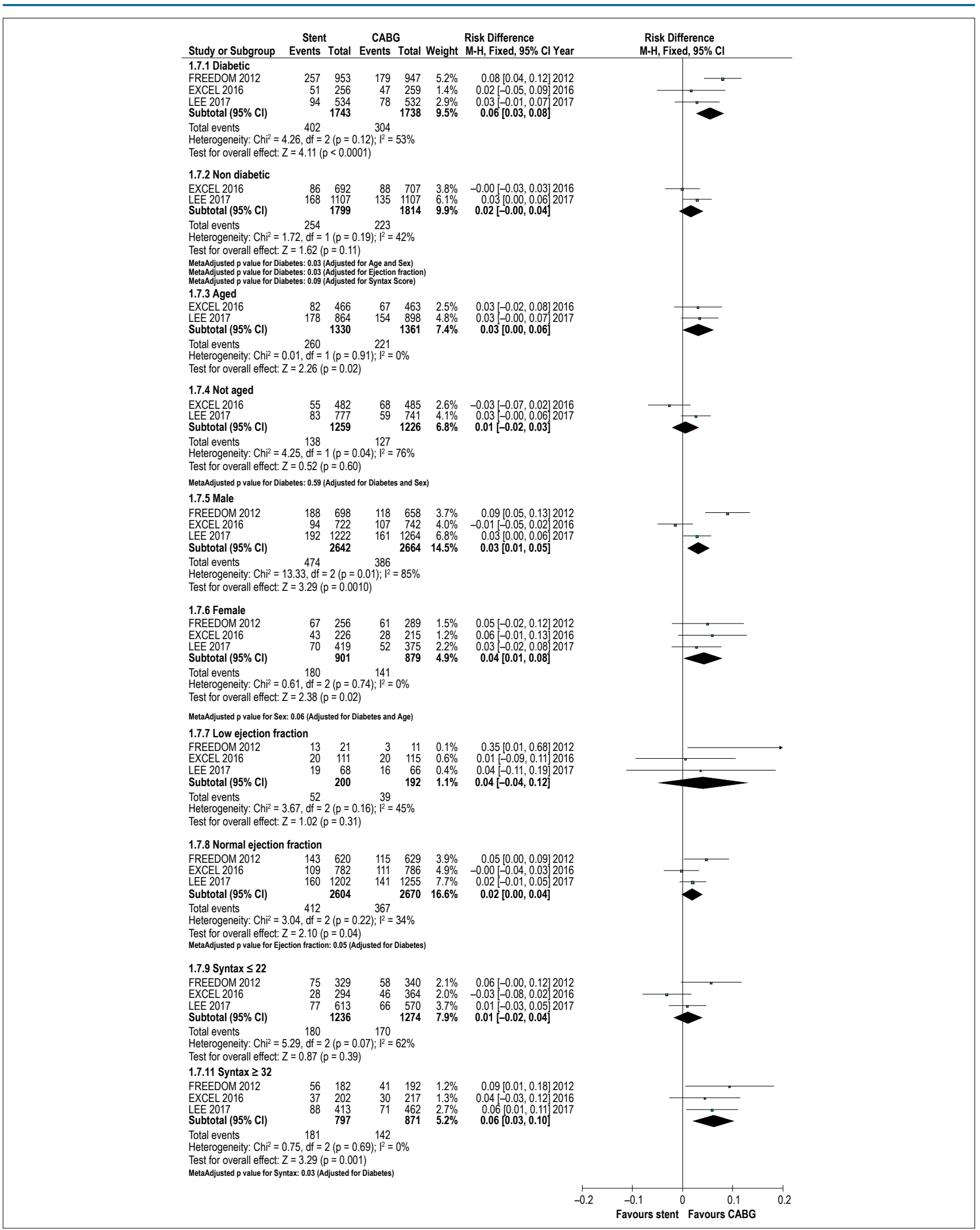

Figure 5 - Stent versuS CABG: risk difference of long-term major composite adverse outcomes (MACCE) in subgroups. The size of each box is proportional to the number of patients of the subgroups. The bars represent $95 \%$ confidence interval. The diamond represents the syntheses of results. CABG: coronary artery bypass grafting. LEE = Lee et al, J Am Coll Cardiol Intv 2016; 9:2481-9 (Meta-analysis of individual patient data of SYNTAX, PRECOMBAT and BEST); EXCEL: Coronary Artery Bypass Surgery for Effectiveness of Left Main Revascularization; FREEDOM, Future Revascularization Evaluation in Patients with Diabetes Mellitus. Low ejection Fraction was defined as $<50 \%$ in EXCEL and as $<40 \%$ in FREEDOM and LEE. 


\begin{tabular}{|c|c|c|c|c|c|c|c|c|}
\hline \multirow{2}{*}{$\begin{array}{l}\text { Study or Subgroup } \\
\text { New reavascularization }\end{array}$} & $\begin{array}{l}\text { Stent } \\
\text { Events }\end{array}$ & Total & \multicolumn{2}{|c|}{ CABG } & Weight & $\begin{array}{l}\text { Risk Difference } \\
\text { M-H, Fixed, } 95 \% \mathrm{Cl} \text { Year }\end{array}$ & \multicolumn{2}{|c|}{$\begin{array}{l}\text { Risk Difference } \\
\text { M-H, Fixed, } 95 \% \mathrm{Cl}\end{array}$} \\
\hline & & & & & & & & \\
\hline AWESOME 1995 & 24 & 222 & 9 & 232 & $3.5 \%$ & $0.07[0.02,0.12] 1995$ & & $\longrightarrow$ \\
\hline MASS I| 1995 & 25 & 203 & 8 & 203 & $3.2 \%$ & $0.08[0.03,0.14] 1995$ & & 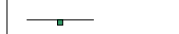 \\
\hline SOS 1995 & 100 & 500 & 30 & 500 & $7.8 \%$ & $0.14[0.10,0.18] 1995$ & & $\multimap-$ \\
\hline ARTS 1996 & 134 & 605 & 57 & 605 & $9.5 \%$ & $0.13[0.09,0.17] 1996$ & & $\square$ \\
\hline ERACI II 1996 & 35 & 225 & 10 & 225 & $3.5 \%$ & $0.11[0.06,0.17] 1996$ & & $\longrightarrow$ \\
\hline LE MANS 2001 & 15 & 53 & 5 & 53 & $0.8 \%$ & $0.19[0.04,0.33] 2001$ & & \\
\hline CARDIA 2002 & 29 & 248 & 5 & 248 & $3.9 \%$ & $0.10[0.05,0.14] 2002$ & & $\longrightarrow$ \\
\hline PRECOMBAT 2002 & 18 & 300 & 10 & 300 & $4.7 \%$ & $0.03[-0.01,0.06] 2002$ & & $\square$ \\
\hline BOUDRIOT 2003 & 14 & 101 & 6 & 101 & $1.6 \%$ & $0.08[-0.00,0.16] 2003$ & & $=$ \\
\hline FREEDOM 2003 & 120 & 947 & 50 & 947 & $14.8 \%$ & $0.07[0.05,0.10] 2003$ & & $\square$ \\
\hline SINTAX 2005 & 128 & 897 & 54 & 897 & $14.0 \%$ & $0.08[0.05,0.11] 2005$ & & $\square$ \\
\hline VACARDS 2006 & 12 & 97 & 11 & 97 & $1.5 \%$ & $0.01[-0.08,0.10] 2006$ & & - \\
\hline BEST 2008 & 30 & 442 & 15 & 442 & $6.9 \%$ & $0.03[0.01,0.06] 2008$ & & $\square$ \\
\hline NOBLE 2008 & 69 & 592 & 44 & 592 & $9.3 \%$ & $0.04[0.01,0.08] 2008$ & & $\square$ \\
\hline EXCEL 2010 & 122 & 957 & 72 & 957 & $15.0 \%$ & $0.05[0.03,0.08] 2010$ & & $\rightarrow-$ \\
\hline Total $(95 \% \mathrm{Cl})$ & & 6389 & & 6399 & $100.0 \%$ & $0.08[0.07,0.09]$ & & $\Delta$ \\
\hline Total events & 875 & & 386 & & & & & \\
\hline \multicolumn{7}{|c|}{ Heterogeneity: $\mathrm{Chi}^{2}=46.43, \mathrm{df}=14(p<0.0001) ; I^{2}=70 \%$} & $\begin{array}{l}-0.2-0.1 \quad 0 \\
\text { Favours stent }\end{array}$ & 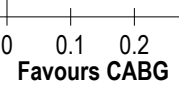 \\
\hline \multicolumn{9}{|c|}{ New reavascularization by alternative procedure } \\
\hline MASS II 1995 & 17 & 203 & 7 & 203 & $5.3 \%$ & $0.05[0.00,0.09] 1995$ & & $\square$ \\
\hline SOS 1995 & 45 & 500 & 25 & 500 & $13.1 \%$ & $0.04[0.01,0.07] 1995$ & & $\square$ \\
\hline ARTS 1996 & 41 & 605 & 50 & 605 & $15.9 \%$ & $-0.01[-0.04,0.01] 1996$ & $\rightarrow$ & t \\
\hline LE MANS 2001 & 4 & 53 & 5 & 53 & $1.4 \%$ & $-0.02[-0.12,0.09] 2001$ & $\Delta$ & - \\
\hline SINTAX 2005 & 25 & 897 & 42 & 897 & $23.6 \%$ & $-0.02[-0.04,-0.00] 2005$ & $\rightarrow$ & \\
\hline NOBLE 2008 & 18 & 592 & 42 & 592 & $15.6 \%$ & $-0.04[-0.07,-0.02] 2008$ & $\rightarrow$ & \\
\hline EXCEL 2010 & 33 & 957 & 65 & 957 & $25.1 \%$ & $-0.03[-0.05,-0.01] 2010$ & $\rightarrow$ & \\
\hline Total $(95 \% \mathrm{Cl})$ & & 3807 & & 3807 & $100.0 \%$ & $-0.01[-0.02,-0.00]$ & $\Delta$ & 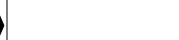 \\
\hline Total events & 183 & & 236 & & & & & \\
\hline \multicolumn{7}{|c|}{$\begin{array}{l}\text { Heterogeneity: } \mathrm{Chi}^{2}=27.10, \mathrm{df}=6(p=0.0001) ; I^{2}=78 \% \\
\text { Test for overall effect: } Z=2.67(p=0.007)\end{array}$} & $\begin{array}{ll}\mid & 1 \\
-0.2 & -0.1\end{array}$ & $\begin{array}{lll}0 & 0.1 & 0.2 \\
& \text { Favours } & \text { CABG }\end{array}$ \\
\hline
\end{tabular}

Figure 6 - Stent versus CABG: new revascularization (top) and new revascularization by alternative procedure (bottom). The size of each box is proportional to the number of patients of the trial. The bars represent $95 \%$ confidence interval. The diamond represents the syntheses of results. DES: trials of the drug-eluting stent era; BMS: trials of the bare-metal stent trials era; CABG: coronary artery bypass grafting; ARTS: Arterial Revascularization Therapies Study; AWESOME: Angina with extremely severe outcomes; ERACI II: Argentine randomized study: coronary angioplasty with stenting versus coronary bypass surgery in patients with multi-vessel disease; MASS II: Medicine, Angioplasty, or Surgery Study; SOS: Stent or Surgery trial; BEST: Bypass Surgery and Everolimus-Eluting Stent Implantation in the Treatment of Patients with Multi-vessel Coronary Artery; Boldriot, trial of Boldriot et al: J Am Coll Cardiol. 2011; 57: 538-545. CARDia: Coronary artery revascularization in diabetic; LE MANS: Left main coronary artery stenting; EXCEL: Coronary Artery Bypass Surgery for Effectiveness of Left Main Revascularization; FREEDOM: Future Revascularization Evaluation in Patients with Diabetes Mellitus; NOBLE: Nordic-Baltic-British Left Main Revascularization Study; PRECOMBAT: Premier of Randomized Comparison of Bypass Surgery versus Angioplasty Using Sirolimus-Eluting Stent in Patients with Left Main Coronary Artery Disease; SYNTAX: Synergy between PCI with Taxus and Cardiac Surgery; Va-Cards: Coronary Artery Revascularization in Diabetes in VA Hospitals.

having similar mortality results, for patients with LMCAD of low or intermediate complexity (SYNTAX score $<33$ ). This may also be the case for multi-vessel disease patients with lesions of low complexity (SYNTAX score $<23$ ). For all other patients, particularly if diabetics, surgery remains the best form of revascularization. There is the possibility that second-generation DES and a more functional strategy, using free fractional reserve and avoiding unnecessary revascularizations will improve the comparative results of $\mathrm{PCI}$ in the future. The one year results of the SYNTAX ${ }^{36}{ }^{36}$ study suggests that this will be true, but long-term follow-up is waited and a randomized trial with contemporary $\mathrm{CABG}$ is warranted.
The present study presents important limitations. It is a meta-analysis of published data and not a collaborative meta-analysis with access to individual data of patients. The inclusion of BMS era trials can also be criticized. It should also be noted that 30 days mortality and late mortality showed moderate heterogeneity, reducing the robustness of our results. Otherwise, our findings apply only to patients for whom revascularization may be performed using either method, without high surgical risk, no history of prior surgical revascularization, normal or near-normal ejection fraction and with the procedures carried out in institutions of excellence. 


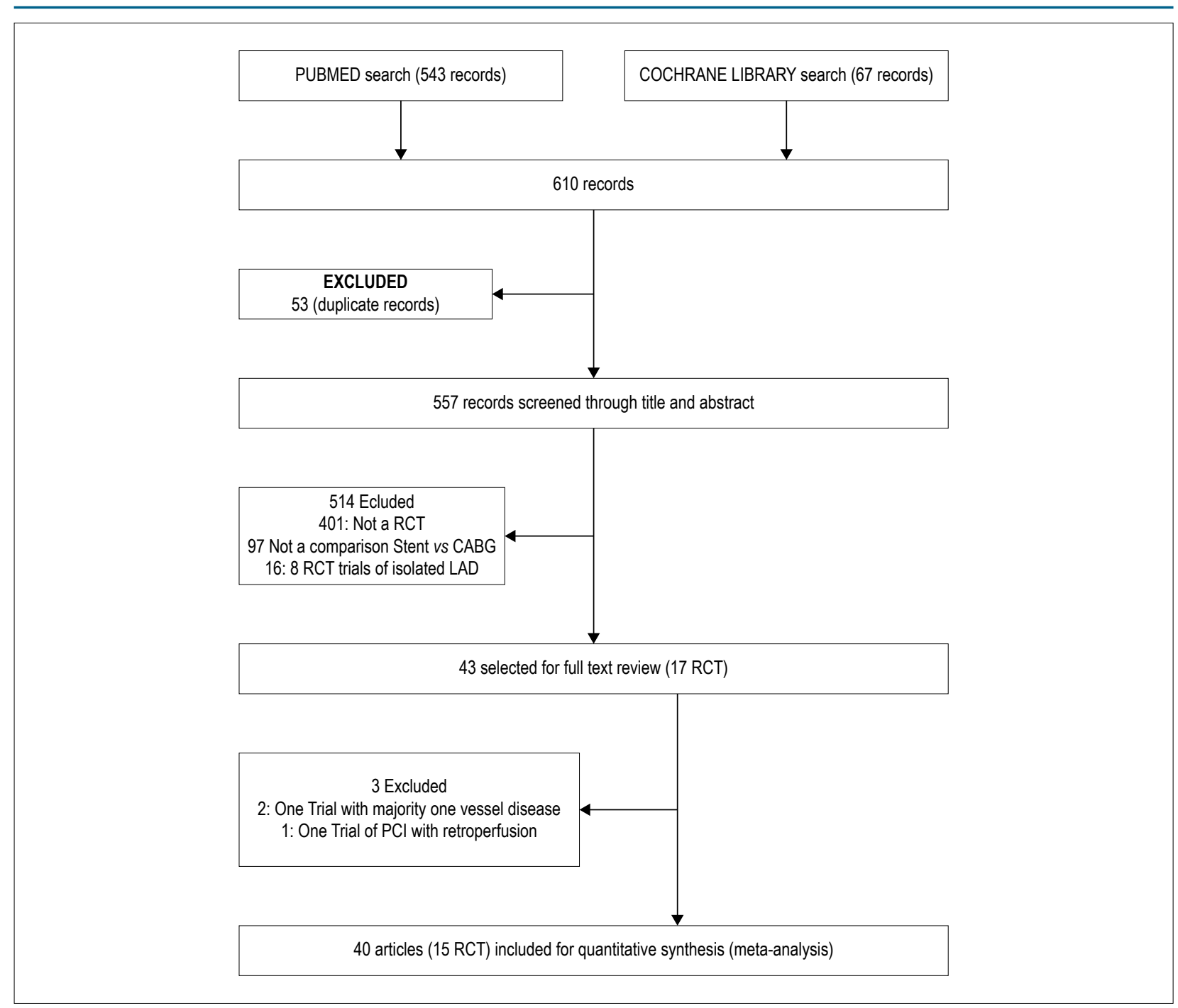

Figure 7 - Study Flow Diagram. RCT: randomized controlled trial; CABG: coronary artery bypass grafting; LAD: left anterior descending; PCl: percutaneous coronary intervention.

\section{Conclusion}

$\mathrm{PCl}$ using stents when compared to CABG was associated with a trend to lower mortality at 30 days, similar one-year mortality, lower incidence of stroke up to one-year, and a trend to higher long-term mortality. There was no long-term mortality difference in non-diabetics and in LMCAD patients. In terms of composite adverse outcomes, the SYNTAX score and diabetes were the most important factors to consider when choosing between the two methods of revascularization.

\section{Author contributions}

Conception and design of the research and critical revision of the manuscript for intellectual content: Andrade PJN; acquisition of data: Andrade PJN, Falcão JLAA, Falcão BAA; analysis and interpretation of the data and writing of the manuscript: Andrade PJN, Falcão JLAA, Falcão BAA, Rocha HAL; statistical analysis: Rocha HAL.

\section{Potential Conflict of Interest}

No potential conflict of interest relevant to this article was reported.

\section{Sources of Funding}

There were no external funding sources for this study.

\section{Study Association}

This study is not associated with any thesis or dissertation work.

\section{Ethics approval and consent to participate}

This article does not contain any studies with human participants or animals performed by any of the authors. 


\section{References}

1. Morrison DA, Sethi G, Sacks J, Henderson W, Grover F, Sedlis S, et al. Percutaneous coronary intervention versus coronary artery bypass graft surgery for patients with medically refractory myocardial ischemia and risk factors for adverse outcomes with bypass: a multicenter, randomized trial. Investigators of the Department of Veterans Affairs Cooperative Study \#385, the Angina With Extremely Serious Operative Mortality Evaluation (AWESOME). J Am Coll Cardiol. 2001;38(1):143-9.

2. Rodriguez A, Bernardi V, Navia J, Baldi J, Grinfield L, Martinez J, et al. Argentine Randomized Study: Coronary Angioplasty with Stenting versus Coronary Bypass Surgery in patients with Multiple-Vessel Disease (ERACI II): 30-day and one-year follow-up results. ERACI II Investigators. J Am Coll Cardiol. 2001;37(1): 51-8.

3. Rodriguez AE, Baldi J, Fernández Pereira C, Navia J, Rodriguez Alemparte M, Delacasa A, et al. Five-year follow-up of the Argentine randomized trial of coronary angioplasty with stenting versus coronary bypass surgery in patients with multiple vessel disease (ERACI II). J Am Coll Cardiol. 2005;46(4):582-8.

4. Hueb W, Soares PR, Gersh BJ, Cesar LA, Luz PL, Puig LB, et al. The medicine, angioplasty, or surgery study (MASS-II): a randomized, controlled clinical trial of three therapeutic strategies for multivessel coronary artery disease: one-year results. J Am Coll Cardiol. 2004;43(10):1743-51.

5. Hueb W, Lopes NH, Gersh BJ, Soares P, Machado LA, Jatene FB, et al. Fiveyear follow-up of the Medicine, Angioplasty, or Surgery Study (MASS II): a randomized controlled clinical trial of 3 therapeutic strategies for multivessel coronary artery disease. Circulation. 2007;115(9):1082-9.

6. Hueb W, Lopes N, Gersh BJ, Soares PR, Ribeiro EE, Pereira AC, et al. Ten-year follow-up survival of the Medicine, Angioplasty, or Surgery Study (MASS II): a randomized controlled clinical trial of 3 therapeutic strategies for multivessel coronary artery disease. Circulation. 2010;122(10):949-57.

7. SOS investigators. Coronary artery bypass surgery versus percutaneous coronary intervention with stent implantation in patients with multivessel coronary artery disease (the Stent or Surgery trial): a randomised controlled trial. Lancet. 2002;360(9338):965-70.

8. Booth J, Clayton T, Pepper J, Nugara F, Flather M, Sigwart U, et al Randomized, controlled trial of coronary artery bypass surgery versus percutaneous coronary intervention in patients with multivessel coronary artery disease: six-year follow-up from the Stent or Surgery Trial (SoS). Circulation. 2008;118(4):381-8.

9. Serruys PW, Unger F, Sousa JE, Jatene A, Bounier HJ, Schomberger JP, et al. Comparison of coronary-artery bypass surgery and stenting for the treatment of multivessel disease. N Engl J Med. 2001;344(15):1117-24.

10. Serruys PW, Ong AT, van Herwerden LA, Sousa JE, Jatene A, Bonnier JJ, et al. Five-year outcomes after coronary stenting versus bypass surgery for the treatment of multivessel disease: the final analysis of the Arterial Revascularization Therapies Study (ARTS) randomized trial. J Am Coll Cardiol. 2005;46(4):575-81.

11. Buszman PE, Kiesz SR, BochenckA, Peszek-Przrya E, Szkiobka I, Debwski M, et al. Acute and late outcomes of unprotected left main stenting in comparison with surgical revascularization. J Am Coll Cardiol. 2008;51(5):538-545.

12. Serruys PW, Morice MC, Kappetei AP, Colombo A, Holmes DR, Mack MJ, et al. Percutaneous coronary intervention versus coronary-artery bypass grafting for severe coronary artery disease. N Eng J Med. 2009;360(10):961-72.

13. Mohr FW, Morice MC, Kappetein AP, Feldman TE, Ståhle E, Colombo A et al. Coronary artery bypass graft surgery versus percutaneous coronary intervention in patients with three-vessel disease and left main coronary disease: 5 -year follow-up of the randomised, clinical SYNTAX trial. Lancet. 2013;381(9867):629-38.

14. Morice MC, Serruys PW, Kappetein AP, Feldman TE, Ståhle E, Colombo A, et al. Five-year outcomes in patients with left main disease treated with either percutaneous coronary intervention or coronary artery bypass grafting in the synergy between percutaneous coronary intervention with taxus and cardiac surgery trial. Circulation. 2014;129(23):2388-94.

15. Kapur A, Hall RJ, Macik IS, Qureshi AC, Butts J, de Belder M, et al. Randomized comparison of percutaneous coronary intervention with coronary artery bypass grafting in diabetic patients. 1-year results of the CARDia (Coronary Artery Revascularization In Diabetics) trial. J Am Coll Cardiol. 2010;55(5):432-40.

16. Boudriot E, Thiele H, Walther T, Liebetrau C, Boeckstegers P, Pohl T, et al. Randomized comparison of percutaneous coronary intervention with Sirolimus eluting stents versus coronary artery bypass grafting in unprotected in unprotected left main stenosis. J Am Coll Cardiol. 2011;57(5):538-45

17. Park SJ, Kim YH, Park DW, Yun SC, Ahn JM, Song HG, et al. Randomized trial of stents versus bypass surgery for left main coronary artey disease. N Engl J Med. 2011;364(18):1718-27.

18. Ahn JM, Roh JH, Kim YH, Park DW, Yun SC, Lee PH, et al. Randomized Trial of Stents Versus Bypass Surgery for Left Main Coronary Artery Disease: 5-Year Outcomes of the PRECOMBAT Study. J Am Coll Cardiol. 2015;65(20):2198-206

19. Kamalesh M, Shap TG, Tang C, Shunk K, Ward HB, Walsh J, et al Percutaneous coronary intervention versus Coronary artery bypass surgery in United States veterans with diabetes. J Am Coll Cardiol. 2013,61(8):807-16.

20. Farkouh ME, Dornanski M, Sleeper LA, Siami FS, Dangas G, Mack M, et al Strategies for multivessel revascularization in patients with diabetes. N Engl J Med. 2012;367(25):2375-84.

21. Park SJ, Ahn KM, Kim YH, Park DW, Yun SC, Lee JY, et al. Trial of everolimuseluting stents or bypass surgery for coronary disease. N Engl J Med. 2015; 372(13):1204-12.

22. Makikallia T, Holm NR, Lindsay M, Spence MS, Erglis A, Menown $I B$, et al. Percutaneous coronary angioplasty versus coronary artery bypass grafting in treatment of unprotected left main stenosis (NOBLE): a prospective, randomized, open-label, non-inferiority trial. Lancet. 2016;388(10061):2743-52.

23. Stone GW, Sabik JF, Serruys PW, Simonton CA, Généreux P, Puskas J, et al Everolimus-stenting or bypass surgery for left main coronary artery disease. N Engl J Med. 2016;375(23):2223-35.

24. Bravata DM, Gienger AL, McDonad KM, Sundaram V, Perez MV, Varghese $\mathrm{R}$, et al. Sistematic review: the comparative effectiveness of percutaneous coronary intervention and coronary artery bypass graft surgery. Ann Intern Med. 2007;147(10):703-16.

25. Hlatky MA, Boothroyd DB, Bravata DM, Boersma E, Booth J, Brooks $\mathrm{MM}$, et al. Coronary artery bypass surgery compared with percutaneous coronary interventions for multivessel disease: a collaborative analysis of individual patient data from ten randomised trials. Lancet. 2009;373(9670):1190-7

26. Smit Y, Valyen J, Kopennaal H, Eefting E, Kappetein AP, Mariani MA. Percutaneous coronary invervention versus coronary artery bypass grafting: a meta-analysis. J Thorac Cardiovasc Surg. 2015;149(3):831-8.

27. Andrade PJ, Medeiros MM, Andrade AT, Lima AA. Coronary angioplasty versus CABG: review of randomized trials. Arq Bras Cardiol. 2011;97(3):e60-9.

28. Andrade PJN, Rocha HAL, Falcão JLAA, Andrade AT, Falcão BAA. Drugeluting stents Versus Coronary Artery Bypass Grafting in Multivessel Disease and Left Main Obstruction: Meta-analysis of Randomized Clinical Trials. Int J Cardiovasc Sci. 2018;31(2):152-62.

29. Lee CW, Ahn JM, Cavalcante R, Sotomi Y, Onuma Y, Suwannasom P, et al. Coronary artery bypass surgery versus drug-eluting stent implantation for left main or multi vessel coronary artery disease: a meta-analysis of individual patient data. JACC Cardiovasc Interv. 2016;9(24):2481-9. 


\section{Original Article}

30. Cavalcante R, Sotomi Y, Lee CW, Ahn JM, Farook V, Tateish H, et al. Outcomes after Percutaneous Coronary intervention and Bypass surgery in patients with unprotected left main disease. J Am Coll Cardiol. 2016:68(10):999-1009.

31. Benedetto U, Gaudino M, Ng C, Biondi-Zoccai G, Dàscenzo F, Frati G, et al. Coronary surgery is superior to drug eluting stents in multivessel disease. Systematic review and meta-analysis of contemporary randomized controlled trials. Int J Cardiol. 2016 May 1;210:19-24.

32. Palmerini T, Serruys P, Kappetein AP, Genereux P, Riva DD, Reggianni LB, et al. Clinical outcomes with percutaneous coronary revascularization versus coronary artery bypass grafting surgery in patients with unprotected left main coronary artery disease: a meta-analysis of six randomized trials and 4,686 patients. Am Heart J. 2017 Aug;190:54-63.
33. Bangalore S, Guo Y, Samadashvili Z, Blecker S, Jinfeng X, Hannan EL. Everolimus-Eluting Stents or Bypass Surgery for Multivessel Coronary Disease. N Eng J Med. 2015;372(13):1213-22.

34. Tong BC, Huber JC, Ascheim DD, Puskas JD, Ferguson TB Jr, Blackstone $\mathrm{EH}$, et al. Weighting composite events endpoints in clinical trials: essential evidence for the heart team. Ann Thorac Surg. 2012;94(6):1908-13.

35. Head SJ, Milojevic M, Daemen J, Ahn JM, Boersma E, Christiansen EH, et al. Mortality after coronary artery bypass grafting versus percutaneous coronary intervention with stenting for coronary artery disease: a polled analysis of individual patient data. Lancet. 2018;391(10124):939-48.

36. Escaned J, Collet C, Ryan N, De Maria GL, Walsh S, Sabate M, et al. Clinical outcomes of state-of-the-art percutaneous coronary revascularization in patients with de novo three vessel disease: 1-year results of the SYNTAX II study. Eur Heart J. 2017;38(42):3124-34. 